\title{
Conundrum of re-positives COVID-19 cases: A Systematic review of Case reports and Case series
}

Authors Information:

Dr Arun Kumar Yadav, MD(Community Medicine), DNB, PhD. Associate Professor, AFMC, arunyadavpsm@gmail.com

Dr Subhadeep Ghosh, MD(Community Medicine), Professor, ACMS, armdoc72@yahoo.co.in

Dr Sudhir Dubey, MD (Microbiology), Associate Professor

\section{Abstract \\ Introduction}

There have been case reports and case series published for RT PCR positive COVID 19 cases that became RT PCR negative but subsequently became RT PCR positive after a symptom free interval following a negative RT PCR test. These cases may include re-positive, reactivated and re-infection cases. Hence, the systematic review to summarize and synthesize evidence from all available case series and case reports published was undertaken.

\section{Methodology}

The systematic review of case series and case reports was registered with Prospero with registration number CRD42020210446. PRISMA guidelines were followed for conducting the systematic review. Studies published in English language only were considered for the Systematic Review. Inclusion criteria for studies included case reports and case series which have documented cases of positive RT-PCR after a period of improvement or negative RT PCR. Reviews, opinions and animal studies were excluded. Case reports which described clinical presentation or manifestations of COVID-19 cases were also excluded from the studies. Methodological quality was assessed using modified Murad scale. 


\section{Results}

A total of 30 case reports/case series were included in the study, wherein a total of 219 cases were included. In re-positive cases, the age range varied from 10 months to 91 years. The pooled proportion using random effects was $12 \%$ with $95 \% \mathrm{Cl}$ from $09 \%$ to $15 \%$. Among the re-positives, a total of 57 cases (26\%) of the cases had co-morbidities. A total of $51(23.3 \%)$ and $17(7.8 \%)$ re-positive cases had been treated with antivirals and corticosteroids respectively. Among the symptomatic cases, the disease severity was lesser as compared to the initial episode of illness. Only a few studies have confirmed the presence of antibodies after the first episode. The few studies that had done contact tracing of re-positives did not find any positive cases among those in contact with re-positives.

\section{Conclusion}

This systematic review presents the review of all the case reports and case series on recurrence of COVID 19 disease. Although limited evidence has been generated due to paucity of such studies and shortcomings in the study designs of case reports and caseseries, nonetheless, the evidence generated can still be used in making clinical decisions and framing policy guidelines

\section{Full article}

Reactivated/relapse/re-positive/re-infection COVID 19 cases: A Systematic review of Case reports and Case series

Introduction

Clusters of cases of atypical pneumonia were reported from Wuhan city, China in Dec 2019 in hubei province (1). The disease was later renamed as COVID-19 and the agent was later identified as Severe Acute Respiratory Syndrome Corona Virus -2(2). WHO 
has declared it as public health emergency of International concern (PHEIC) on 30 Jan 20 and subsequently as a pandemic on 11 Mar 20(3).

As on 16 September 2020 29,444,198 COVID cases and 9,31,321 deaths have been reported globally (4). More than nine months into the pandemic, steady accumulation of scientific data and evidence in the context of disease dynamics, transmission, pathophysiology, diagnostic and treatment modalities, a large number of existing knowledge gaps have gradually been filled; however certain aspects of the disease pertaining to immune response to the disease (Humoral versus Cellular Immunity, persistence of acquired immunity and natural immunity to the disease) are still in a nascent stage of conception. These issues assume greater importance with reports of re-activation/ relapse of the disease creating sensational headlines and the imminent development and marketing of a plethora of vaccines on the anvil.

There have been various case reports and case series published for RT PCR positive COVID -19 cases who have become RT PCR negative and again become RT PCR positive after symptom free period or RT PCR negative test. These cases may include, re-positive, reactivated and reinfection cases. It is not known whether these cases share common characteristics or may share common characteristics which may help in identification prior to their discharge. The systematic review of the case reports and case series of the re-positive may help in better understanding of the natural history of the disease. Hence, systematic review to summarize and synthesize evidence from all the case series and case reports published was undertaken.

\section{Methodology}

The systematic review of case series and case reports was registered with the Prospero with registration number CRD42020210446. PRISMA guidelines were followed for conducting the systematic review. A detailed literature search was done till 12 Sep 2020 for studies having reported cases of COVID-19 after a symptom-free interval. The databases that were searched included Medline through Pubmed, and Cochrane databases. The key term used were COVID-19, Severe Acute Respiratory Syndrome Corona Virus, Relapse, Reactivation and Re-infection. The detailed search for Pubmed is given in supplementary table 1. Hand searches of the references of articles was also 
done. Observational studies including Case Reports and Case Series which have reported COVID -19 cases after a symptom free interval were taken into the systematic review. Studies published in English language only were considered for the Systematic Review. Inclusion criteria for studies includes case reports and case series who have documented cases of positive RT-PCR after period of improvement or negative RT PCR. Review, opinions and animal studies were excluded. Case reports which described clinical presentation or manifestations of COVID-19 cases were also excluded from the studies.

A data extraction form was synthesized and data was extracted by two authors independently. The data items consisted of age and sex of the patients, clinical comorbidities, date of initial positive PCR test, date of negative PCR test based on which the patient was declared as cured and date of positive PCR test in recovered individuals who reported with fresh onset of symptoms suggestive of COVID-19 infection after a disease free interval. Data on serology (If performed) and clinical outcome of patients was also collated.

Methodological quality will be assessed using the existing guidelines (5). The narrative synthesis of the results would be done. The meta-analysis technique for pooling of results would be used wherever possible.

Results:

The selection of the study is shown as PRISMA Chart in Figure 1. A total of 29 case reports/case series were included in the study. A total of 219 cases from 30 studies were included in the study. The details and characteristics of the patients in the case series and case reports are shown in table 1(6-25,25-34).

A total of eight studies gives the proportion of cases who are positive after the follow-up period which ranges from one week to seven weeks. A total of eight studies have mentioned proportion of cases who became repositive after negative RT PCR test. The summary of proportions and their pooled ratio is given in figure 2. The pooled proportion using random effects was $12 \%$ with $95 \% \mathrm{Cl}$ from $09 \%$ to $15 \%$. All studies 
had follow up period of in the range 4-17 days except Jianghong et al which had followup time of 14-46 days.

The age range of the recurrence cases varies from 10 months to 91 years of age. The pooled mean age of 195 cases was $44.3 \pm 19.2$ years. Zhao et al studied recurrence in children and wu et al data for combining the age was not mentioned(21,23). A total of 111 out of 209 were females. Sex was not mentioned for 10 cases.

The COVID 19 testing among discharged patients has been done from sputum ( lower respiratory tract), nasopharyngeal and anal swab the details are shown in table 1.

A total of $136(62.1 ; 95 \% \mathrm{Cl}: 55.3-68.5)$ COVID Cases were symptomatic, However, the status was not known for $70(32 \%)$ COVID cases at initial presentation. Only 12 cases $(5.5: 95 \% \mathrm{Cl} ; 2.8-9,4)$ were of severe cases as reported in the studies. Majority of the cases $(197,89.9 \%)$ had mild-moderate presentation While the presentation was not known for 10 COVID cases. A total of 57 cases (26\%) of the repositives cases have Co-morbidities. A total of 51 and 17 COVID cases had taken antivirals and corticosteroids respectively. A total of $64(29.2 \%)$ reported COVID cases were symptomatic in second episodes, 150 (68.5\%) were asymptomatic and the status of five was unknown. The range of days for positivity varied from 03 days to 101 days after discharge.

Only a few studies confirmed the antibody presence after first episode (table 1). However even after development of antiboides studies have reported re-positivity. Only a few studies have looked into genetic analysis of the SARS COV2 to confirm the reinfection.

Few studies had done contact tracing of repositives, however to date did not find any positive cases in contact with repositives.

The mortality has been reported in seven repositives cases. The age range of these cases varies from 73-91 years. All of them had multiple co-morbidities. 
A total of only 63 reported cases were symptomatic after the first episode, however, the majority of them were less severe than the first episode of COVID 19 cases. Only few studies have shown antibody formation after first episode.

The quality of studies assessed by using the modified Murad et al scale is shown in figure 3. In most of the methods selection methods are not clear and also there were no precautions taken for ruling out false positive or rule out the pathogen.

Korea Centers for Disease Control and Prevention reported 141 cases positive by RT PCR after they recovered from COVID-19(35). However, the probable reason given was relapse or inconsistent tests. The details were not available on the site.

Risk of bias. Though there are no set guidelines for the estimation of the risk of bias, the author feels that initial PCR positive, subsequent PCR negative, serological testing and PCR positive after symptom-free period are essential for draw conclusion about relapse or reinfection. Only case reports by Lafai et al and Enrico et al have reported negative $\operatorname{PCR}(7,8)$. Case reports by Batissee et al and Ravioli et al did not mention a negative PCR test after first COVID infection(6,10). Loncosole et al provided all the requiste information(11)

\section{Discussion}

\section{Definition of relapse}

The systematic review was done of all case reports and case series to identify common characteristics and evidence available for repositives of the cases. Though in literature search we found evidence of repositives of COVID 19 cases after symptoms free and negative RT PCR test, yet it is difficult to ascertain whether it was due to continuous shedding of the virus, relapse, or reinfection of the virus. Only six studies are there which have done the genetic analysis of the COVID 19 virus and found different genetic disease among those who have recovered from the COVID -19.

The recurrence has been observed across all ages from 10 months to 91 years of age. The mortality is seen in older cases with multiple co-morbidities in consonance with the 
primary infection. Immunity of the individual may also influence recurrences. Hence immunosenescent of the old age as well immunosuppressants drugs may affect the recurrence. However, majority of the COVID 19 repositves cases were not given corticosteroids. Many repositives cases were also given antiviral drug. Howerver there is a limitation of making inference from the systematic review as no valid control group were not present and secondly the denominatior in case reports or case series is difficult to ascertain. The effect of other immunomodulator and antiviral drug on recurrence may be studied in well designed study.

The pooled proportion of studies that have given the proportion of COVID 19 repositives was done. Around $12 \%$ of discharged COVID 19 cases after comes out positive. The reasons may be related to Intermittent shedding of virus, the persistence of the virus, testing technique including sampling, or host characteristics. The persistence of virus in body is known phenomenon for SARS-associated Coronavirus(36). As of now there was no evidence of secondary cases from these repositives, however, the possibility of spread of infection does exist. This underlines the importance of surveillance of discharge cases of COVID 19.

Different site for sample may also have some effect as in many cases even if the sample from nasopharyngeal are negative, the samples from sputum ( lower respiratory tract ) and anal swab have been positive. There is an evidence that virus may be shed longer from extraphrangeal site. There are reports that of virus shedding from asymptomatic patients may continue from extrapulmonary sites in various bodily fluids (Saliva, tears, feaces, throat, or nasal discharge) for longer duration of time $(37,38)$. Its role in re-infection is still not known. However there are few studies which suggests no role of shedding of virus on reinfection(39)

Yuan et al noted no difference between among repositves and negatives for antibody formation and also reported that aymptomatic cases may be repositives. The animal studies however have shown the prevention of reinfection with antibody formation(40) The role of antibody in virus shedding and reinfection may needs to be elucidated in further studies. Re-infection may lead to the selection of escape mutants and subsequent dissemination to the population. 
Antibody dependent enhancement is a known phenomenon in viral disease, responsible for increased severity of subsequent infections, However, in this systematic review we found that majority of re-positives cases were milder than first infection. This may be due to reasons that most of the cases are not reinfection but persistence of same infection or interaction between virus-virus. A modelling for reinfection has concluded that the rate of reinfection by the recovered population will decline to zero overtime as the virus is cleared clinically from the system of the recovered class(41)

This systematic review presents the review of all the case reports and case series on recurrence of the diseases. The evidence generated may not be of high level but can still be used in making clinical decision and policy making. Clinician may suspect the COVID cases among recovered cases in which all other diagnosis has been ruled out and policy makers and public health specialist may need to modify the policy as per newer evidence. The infectiousness of these recurrence cases may need to be further explored as this will have major implication on public health policy.

Since these patients of recurrence may represent special subset of COVID cases, the findings may not be generalizable to all COVID cases. More research is needed to delineate the factors responsible for recurrence in cases. As the pandemic progress the evidence would need further revision. Nevertheless, there a strong case for proper documentation of all the cases to further refute or confirm the findings.

\section{References}

1. She J, Jiang J, Ye L, Hu L, Bai C, Song Y. 2019 novel coronavirus of pneumonia in Wuhan, China: emerging attack and management strategies. Clin Transl Med [Internet]. 2020 Feb 20 [cited 2020 Aug 17];9. Available from: https://www.ncbi.nlm.nih.gov/pmc/articles/PMC7033263/

2. Naming the coronavirus disease (COVID-19) and the virus that causes it [Internet]. [cited 2020 Aug 17]. Available from: https://www.who.int/emergencies/diseases/novel- 
medRxiv preprint doi: https://doi.org/10.1101/2020.12.10.20223990; this version posted December $11,2020$. The copyright holder for this preprint (which was not certified by peer review) is the author/funder, who has granted medRxiv a license to display the preprint in perpetuity.

It is made available under a CC-BY-NC 4.0 International license .

coronavirus-2019/technical-guidance/naming-the-coronavirus-disease-(covid-2019)-andthe-virus-that-causes-it

3. Coronavirus (COVID-19) events as they happen [Internet]. [cited 2020 Aug 17]. Available from: https://www.who.int/emergencies/diseases/novel-coronavirus-2019/events-asthey-happen

4. Coronavirus disease (COVID-19) - World Health Organization [Internet]. [cited 2020 Aug 17]. Available from: https://www.who.int/emergencies/diseases/novel-coronavirus-2019

5. Murad MH, Sultan S, Haffar S, Bazerbachi F. Methodological quality and synthesis of case series and case reports. BMJ Evidence-Based Medicine. 2018 Apr 1;23(2):60-3.

6. Batisse D, Benech N, Botelho-Nevers E, Bouiller K, Collarino R, Conrad A, et al. Clinical recurrences of COVID-19 symptoms after recovery: viral relapse, reinfection or inflammatory rebound? J Infect [Internet]. 2020 Jun 30 [cited 2020 Aug 13]; Available from: https://www.ncbi.nlm.nih.gov/pmc/articles/PMC7326402/

7. Lafaie L, Célarier T, Goethals L, Pozzetto B, Sylvain G, Ojardias E, et al. Recurrence or Relapse of COVID-19 in Older Patients: A Description of Three Cases. Journal of the American Geriatrics Society [Internet]. [cited 2020 Aug 13];n/a(n/a). Available from: https://onlinelibrary.wiley.com/doi/abs/10.1111/jgs.16728

8. Bentivegna E, Sentimentale A, Luciani M, Speranza ML, Guerritore L, Martelletti P. New IgM seroconversion and positive RT-PCR test after exposure to the virus in recovered COVID-19 patient. Journal of Medical Virology [Internet]. [cited 2020 Aug 13];n/a(n/a). Available from: https://onlinelibrary.wiley.com/doi/abs/10.1002/jmv.26160

9. Ye G, Pan Z, Pan Y, Deng Q, Chen L, Li J, et al. Clinical characteristics of severe acute respiratory syndrome coronavirus 2 reactivation. J Infect. 2020;80(5):e14-7.

10. Ravioli S, Ochsner H, Lindner G. Reactivation of COVID-19 pneumonia: A report of two cases. J Infect. 2020 Aug;81(2):e72-3.

11. Loconsole D, Passerini F, Palmieri VO, Centrone F, Sallustio A, Pugliese S, et al. Recurrence of COVID-19 after recovery: a case report from Italy. Infection. 2020 May 16;

12. Jiang $M$, Li Y, Han $M$, Wang $Z$, Zhang $Y$, Du X. Recurrent PCR positivity after hospital discharge of people with coronavirus disease 2019 (COVID-19). J Infect. 2020 Jul;81(1):147-78.

13. Chang S-C, Wang J-T, Huang L-M, Chen $\mathrm{Y}-\mathrm{C}$, Fang $\mathrm{C}-\mathrm{T}$, Sheng $\mathrm{W}-\mathrm{H}$, et al. Longitudinal Analysis of Severe Acute Respiratory Syndrome (SARS) Coronavirus-Specific Antibody in SARS Patients. Clin Diagn Lab Immunol. 2005 Dec;12(12):1455-7. 
medRxiv preprint doi: https://doi.org/10.1101/2020.12.10.20223990; this version posted December $11,2020$. The copyright holder for this preprint (which was not certified by peer review) is the author/funder, who has granted medRxiv a license to display the preprint in perpetuity.

It is made available under a CC-BY-NC 4.0 International license .

14. Yoo SY, Lee Y, Lee GH, Kim DH. Reactivation of SARS-CoV-2 after recovery. Pediatrics International. 2020;62(7):879-81.

15. Liu F, Cai Z, Huang J, Yu W, Niu H, Zhang Y, et al. Positive SARS-CoV-2 RNA recurs repeatedly in a case recovered from COVID-19: dynamic results from 108 days of followup. Pathog Dis [Internet]. 2020 Jun 27 [cited 2020 Aug 28]; Available from: https://www.ncbi.nlm.nih.gov/pmc/articles/PMC7337794/

16. Yuan B, Liu H-Q, Yang Z-R, Chen Y-X, Liu Z-Y, Zhang K, et al. Recurrence of positive SARSCoV-2 viral RNA in recovered COVID-19 patients during medical isolation observation. Scientific Reports [Internet]. 2020 Dec [cited 2020 Sep 5];10(1). Available from: http://www.nature.com/articles/s41598-020-68782-w

17. Lan L, Xu D, Ye G, Xia C, Wang S, Li Y, et al. Positive RT-PCR Test Results in Patients Recovered From COVID-19. JAMA. 2020 Apr 21;323(15):1502-3.

18. Cao H, Ruan L, Liu J, Liao W. The clinical characteristic of eight patients of COVID-19 with positive RT-PCR test after discharge. J Med Virol [Internet]. 2020 Jun 2 [cited 2020 Sep 7]; Available from: https://www.ncbi.nlm.nih.gov/pmc/articles/PMC7272974/

19. Deng W, Guang T, Yang M, Li J, Jiang D, Li C, et al. Positive results for patients with COVID19 discharged form hospital in Chongqing, China. BMC Infectious Diseases [Internet]. 2020 Dec [cited 2020 Sep 7];20(1). Available from: https://bmcinfectdis.biomedcentral.com/articles/10.1186/s12879-020-05151-y

20. Peng J, Wang M, Zhang G, Lu E. Seven discharged patients turning positive again for SARSCoV-2 on quantitative RT-PCR. American Journal of Infection Control. 2020 Jun $1 ; 48(6): 725-6$.

21. Wu J, Liu X, Liu J, Liao H, Long S, Zhou N, et al. Coronavirus Disease 2019 Test Results After Clinical Recovery and Hospital Discharge Among Patients in China. JAMA Netw Open. 2020 May 1;3(5):e209759-e209759.

22. Zhou $W, X u X$, Chang $Z$, Wang $H$, Zhong $X$, Tong $X$, et al. The dynamic changes of serum IgM and IgG against SARS-CoV-2 in patients with COVID-19. Journal of Medical Virology [Internet]. [cited 2020 Aug 13];n/a(n/a). Available from: https://onlinelibrary.wiley.com/doi/abs/10.1002/jmv.26353

23. Zhao W, Wang Y, Tang Y, Zhao W, Fan Y, Liu G, et al. Characteristics of Children With Reactivation of SARS-CoV-2 Infection After Hospital Discharge. Clin Pediatr (Phila). 2020 Sep 1;59(9-10):929-32.

24. Li J, Long X, Fang X, Zhang Q, Hu S, Lin Z, et al. SARS-CoV-2 positivity in a discharged COVID-19 patient: a case report. Clinical Microbiology and Infection. 2020 Aug 1;26(8):1115-7. 
medRxiv preprint doi: https://doi.org/10.1101/2020.12.10.20223990; this version posted December $11,2020$. The copyright holder for this preprint (which was not certified by peer review) is the author/funder, who has granted medRxiv a license to display the preprint in perpetuity.

It is made available under a CC-BY-NC 4.0 International license .

25. Chen D, Xu W, Lei Z, Huang Z, Liu J, Gao Z, et al. Recurrence of positive SARS-CoV-2 RNA in COVID-19: A case report. International Journal of Infectious Diseases. 2020 Apr 1;93:2979.

26. Hu R, Jiang Z, Gao H, Huang D, Jiang D, Chen F, et al. Recurrent Positive Reverse Transcriptase-Polymerase Chain Reaction Results for Coronavirus Disease 2019 in Patients Discharged From a Hospital in China. JAMA Netw Open. 2020 May 1;3(5):e2010475e2010475.

27. An J, Liao X, Xiao T, Qian S, Yuan J, Ye H, et al. Clinical characteristics of the recovered COVID-19 patients with re-detectable positive RNA test. medRxiv. 2020 Mar 30;2020.03.26.20044222.

28. Duggan NM, Ludy SM, Shannon BC, Reisner AT, Wilcox SR. A case report of possible novel coronavirus 2019 reinfection. American Journal of Emergency Medicine [Internet]. 2020 Jan 1 [cited 2020 Aug 13]; Available from:

https://covid19.elsevierpure.com/fi/publications/a-case-report-of-possible-novelcoronavirus-2019-reinfection

29. Positive result of Sars-Cov-2 in sputum from a cured patient with COVID-19 | Elsevier Enhanced Reader [Internet]. [cited 2020 Sep 7]. Available from:

https://reader.elsevier.com/reader/sd/pii/S1477893920300879?token=8E8AB4EE43A1E6 B85A023FA137DA6C98C2B181CF501166FF1985F274B2F80305ED97584903CA626907762F 333E0067EA

30. To KK-W, Hung IF-N, Ip JD, Chu AW-H, Chan W-M, Tam AR, et al. COVID-19 re-infection by a phylogenetically distinct SARS-coronavirus- 2 strain confirmed by whole genome sequencing. Clin Infect Dis. 2020 Aug 25;

31. Tillett RL, Sevinsky JR, Hartley PD, Kerwin H, Crawford N, Gorzalski A, et al. Genomic evidence for reinfection with SARS-CoV-2: a case study. The Lancet Infectious Diseases [Internet]. 2020 Oct 12 [cited 2020 Oct 13];0(0). Available from: https://www.thelancet.com/journals/laninf/article/PIIS1473-3099(20)30764-7/abstract

32. Van Elslande J, Vermeersch $\mathrm{P}$, Vandervoort K, Wawina-Bokalanga T, Vanmechelen B, Wollants E, et al. Symptomatic SARS-CoV-2 reinfection by a phylogenetically distinct strain. Clin Infect Dis. 2020 Sep 5;

33. Prado-Vivar B, Becerra-Wong M, Guadalupe JJ, Marquez S, Gutierrez B, Rojas-Silva P, et al. COVID-19 Re-Infection by a Phylogenetically Distinct SARS-CoV-2 Variant, First Confirmed Event in South America. [Internet]. Rochester, NY: Social Science Research Network; 2020 Sep [cited 2020 Oct 13]. Report No.: ID 3686174. Available from: https://papers.ssrn.com/abstract=3686174 
medRxiv preprint doi: https://doi.org/10.1101/2020.12.10.20223990; this version posted December $11,2020$. The copyright holder for this preprint (which was not certified by peer review) is the author/funder, who has granted medRxiv a license to display the preprint in perpetuity.

It is made available under a CC-BY-NC 4.0 International license .

34. Gupta V, Bhoyar RC, Jain A, Srivastava S, Upadhayay R, Imran M, et al. Asymptomatic reinfection in two healthcare workers from India with genetically distinct SARS-CoV-2. Clin Infect Dis [Internet]. 2020 Sep 23 [cited 2020 Oct 14]; Available from: https://www.ncbi.nlm.nih.gov/pmc/articles/PMC7543380/

35. www.ETHealthworld.com. Why are some S.Koreans who recovered from the coronavirus testing positive again?? - ET HealthWorld [Internet]. ETHealthworld.com. [cited 2020 Aug 15]. Available from: https://health.economictimes.indiatimes.com/news/industry/whyare-some-s-koreans-who-recovered-from-the-coronavirus-testing-positive-again$/ 75178047$

36. Isakbaeva ET, Khetsuriani N, Beard RS, Peck A, Erdman D, Monroe SS, et al. SARSassociated Coronavirus Transmission, United States. Emerg Infect Dis. 2004 Feb;10(2):22531.

37. Kalkeri R, Goebel S, Sharma GD. SARS-CoV-2 Shedding from Asymptomatic Patients: Contribution of Potential Extrapulmonary Tissue Reservoirs. The American Journal of Tropical Medicine and Hygiene. $2020 \mathrm{Jul}$ 8;103(1):18-21.

38. Du W, Yu J, Liu X, Chen H, Lin L, Li Q. Persistence of SARS-CoV-2 virus RNA in feces: A case series of children. Journal of Infection and Public Health. 2020 Jul 1;13(7):926-31.

39. No infectious risk of COVID-19 patients with long-term fecal 2019-nCoV nucleic acid positive [Internet]. European Review. 2020 [cited 2020 Aug 15]. Available from: https://www.europeanreview.org/article/21370

40. Bao L, Deng W, Gao H, Xiao C, Liu J, Xue J, et al. Reinfection could not occur in SARS-CoV-2 infected rhesus macaques. bioRxiv. 2020 Mar 14;2020.03.13.990226.

41. Okhuese AV. Estimation of the Probability of Reinfection With COVID-19 by the Susceptible-Exposed-Infectious-Removed-Undetectable-Susceptible Model. JMIR Public Health and Surveillance [Internet]. 2020 Jun [cited 2020 Aug 24];6(2). Available from: https://www.ncbi.nlm.nih.gov/pmc/articles/PMC7223428/ 
medRxiv preprint doi: https://doi.org/10.1101/2020.12.10.20223990; this version posted December 11, 2020. The copyright holder for this preprint (which was not certified by peer review) is the author/funder, who has granted medRxiv a license to display the preprint in perpetuity.

It is made available under a CC-BY-NC 4.0 International license.

Fig: 1 Prisma Chart for the inclusion of studies in the systematic review.

\begin{tabular}{|l|}
\hline I \\
$D$ \\
$E$ \\
$N$ \\
$T$ \\
I \\
$F$ \\
I \\
$C$ \\
$A$ \\
$T$ \\
I \\
$O$ \\
$N$ \\
\hline
\end{tabular}

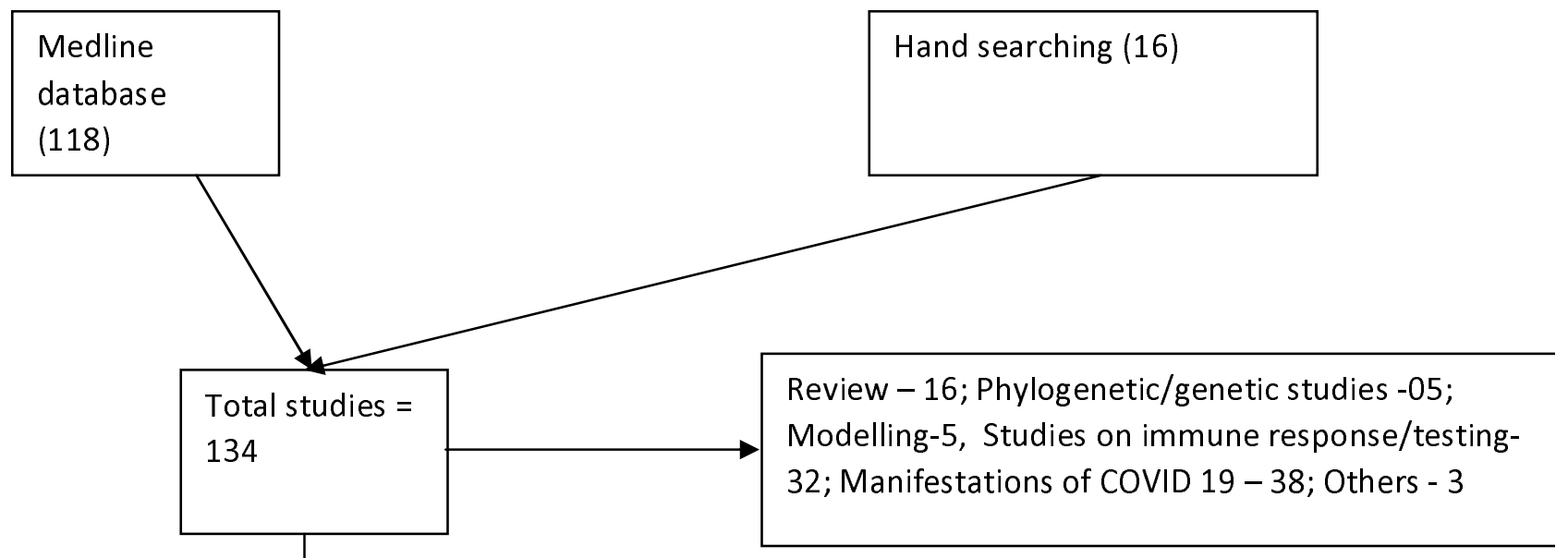

\begin{tabular}{|l|}
\hline$S$ \\
$C$ \\
$R$ \\
$E$ \\
$E$ \\
$N$ \\
I \\
$N$ \\
G \\
\hline
\end{tabular}
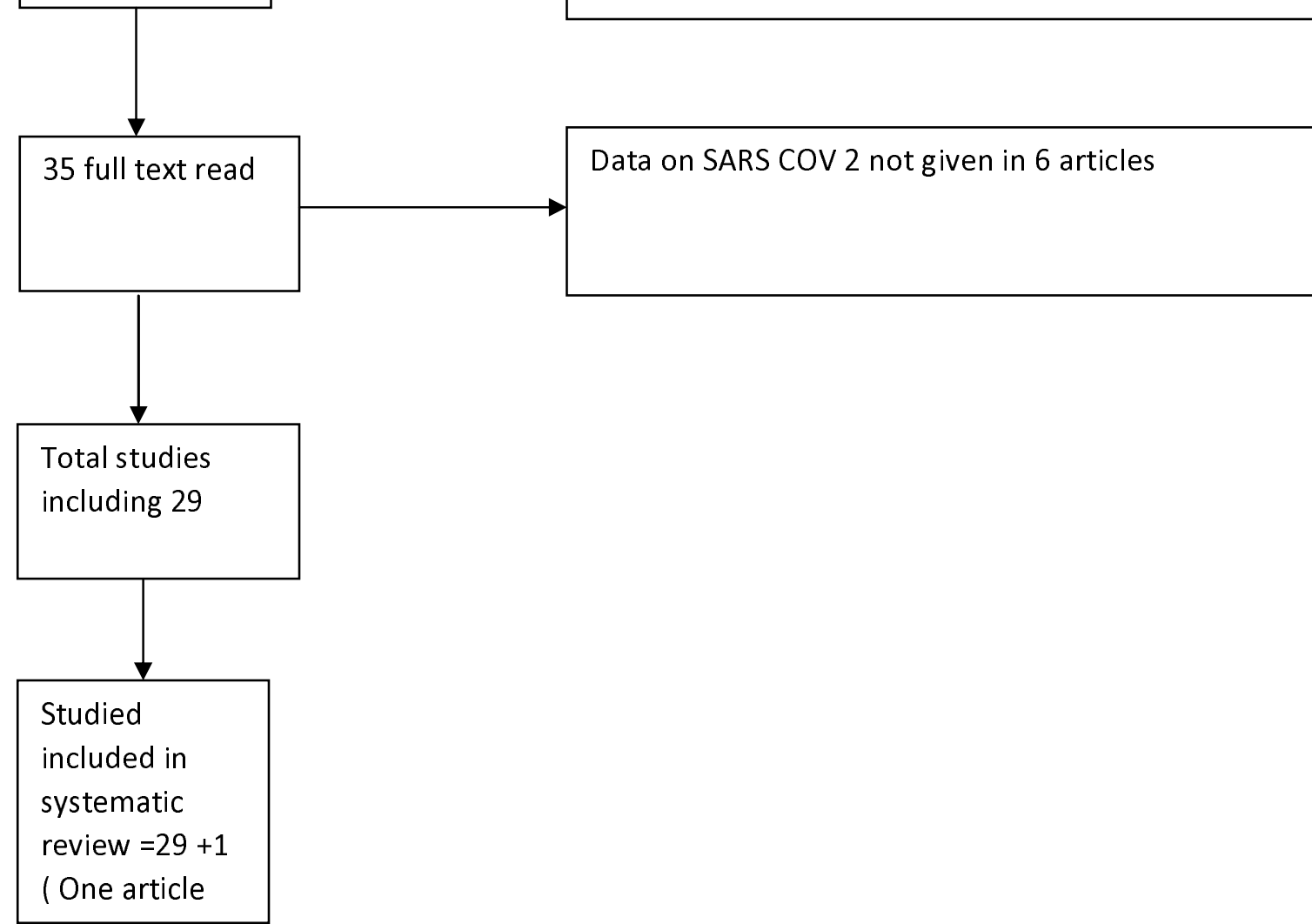

Data on SARS COV 2 not given in 6 articles 
medRxiv preprint doi: https://doi.org/10.1101/2020.12.10.20223990; this version posted December 11, 2020. The copyright holder for this preprint (which was not certified by peer review) is the author/funder, who has granted medRxiv a license to display the preprint in perpetuity.

It is made available under a CC-BY-NC 4.0 International license.

Figure 2: Pooled proportions from studies.

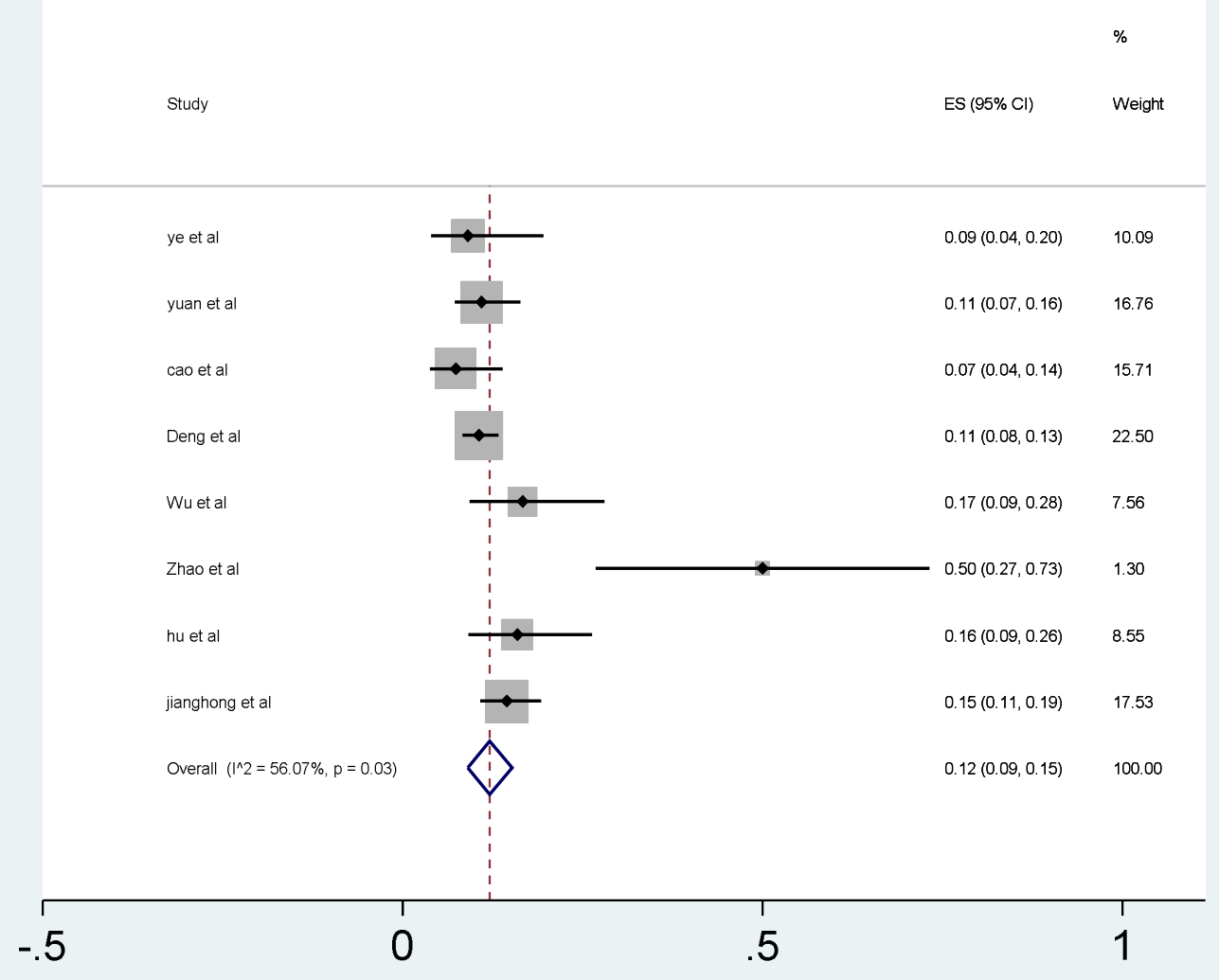


medRxiv preprint doi: https://doi.org/10.1101/2020.12.10.20223990; this version posted December 11, 2020. The copyright holder for this preprint (which was not certified by peer review) is the author/funder, who has granted medRxiv a license to display the preprint in perpetuity.

It is made available under a CC-BY-NC 4.0 International license .

Figure 3: Quality of study as assessed using modified

Replicate the research or to make inferences

Was follow-up long enough for outcomes

Precautions taken for ruling out false positive/rule out other pathogen

RT PCR positive ascertained

RT PCR negative test ascertained

Selection method

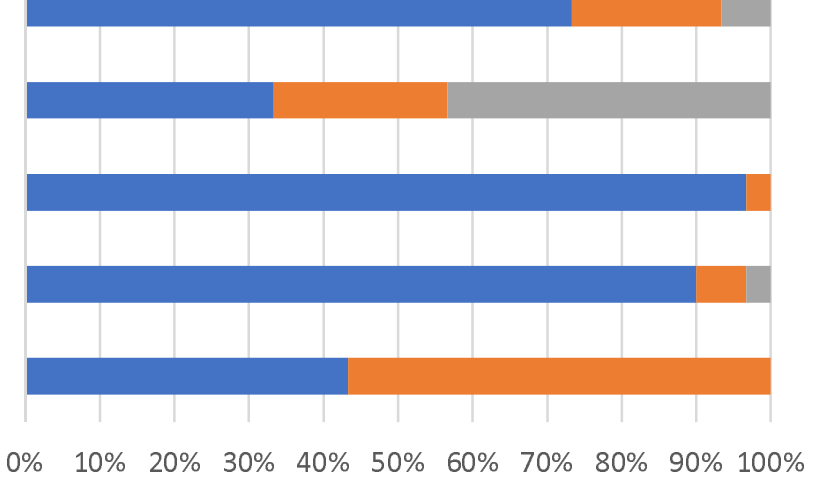

Yes $\square$ No $\mathrm{NM}$ 
medRxiv preprint doi: https://doi.org/10.1101/2020.12.10.20223990; this version posted December 11, 2020. The copyright holder for this preprint (which was not certified by peer review) is the author/funder, who has granted medRxiv a license to display the preprint in perpetuity.

It is made available under a CC-BY-NC 4.0 International license .

Table 1 : Characteristic of studies

\begin{tabular}{|c|c|c|c|c|c|c|c|c|c|c|c|c|c|c|}
\hline $\begin{array}{l}\text { n } \\
\text { o }\end{array}$ & Study & $\begin{array}{l}\text { Age } \\
\text { and } \\
\text { sex }\end{array}$ & $\begin{array}{l}\text { Coun } \\
\text { try }\end{array}$ & $\begin{array}{l}\text { Sy } \\
\text { mp } \\
t\end{array}$ & $\begin{array}{l}\text { Co- } \\
\text { morbi } \\
\text { dity }\end{array}$ & $\begin{array}{l}\text { Sev } \\
\text { erity }\end{array}$ & $\begin{array}{l}\text { Date } \\
\text { of } \\
\text { First } \\
\text { COVI } \\
\text { D } 19 \\
\text { (PCR } \\
\text { ) }\end{array}$ & $\begin{array}{l}\text { Te } \\
\text { st } \\
\text { Do } \\
\text { ne }\end{array}$ & $\begin{array}{l}\text { Serolo } \\
\text { gical } \\
\text { test } \\
\text { done } \\
\text { after } \\
\text { first } \\
\text { episod } \\
\text { e }\end{array}$ & $\begin{array}{l}\text { RT } \\
P C \\
R \\
\text { neg } \\
\text { ativ } \\
e \\
\text { afte } \\
r \\
\text { first } \\
\text { epi } \\
\text { sod } \\
\text { e }\end{array}$ & $\begin{array}{l}\text { Sympt } \\
\text { omatic } \\
\text { again } \\
\text { after } \\
\text { period } \\
\text { of } \\
\text { weeks }\end{array}$ & $\begin{array}{l}\text { Date } \\
\text { of } \\
\text { Seco } \\
\text { nd } \\
\text { COV } \\
\text { ID } \\
19\end{array}$ & $\begin{array}{l}\text { Test } \\
\text { done }\end{array}$ & $\begin{array}{l}\text { Outc } \\
\text { ome }\end{array}$ \\
\hline 1 & $\begin{array}{l}\text { Batiss } \\
\text { e et al } \\
1 \\
2 \\
3 \\
4 \\
5 \\
6 \\
7 \\
8 \\
9 \\
10 \\
11\end{array}$ & $\begin{array}{l}19, \\
F \\
32, \\
F \\
33, \\
F \\
43 \\
M \\
85, \\
M \\
54, \\
M \\
91 \\
F \\
55, \\
M \\
72, \\
M \\
73 \\
M \\
84, \\
F\end{array}$ & $\begin{array}{l}\text { Fran } \\
\text { ce }\end{array}$ & $\begin{array}{l}Y e \\
\mathrm{~s} \\
\mathrm{Ye} \\
\mathrm{s} \\
\mathrm{Ye} \\
\mathrm{s} \\
\mathrm{Ye} \\
\mathrm{s} \\
\mathrm{Ye} \\
\mathrm{s} \\
\mathrm{Ye} \\
\mathrm{s} \\
\mathrm{Ye} \\
\mathrm{s} \\
\mathrm{Ye} \\
\mathrm{s} \\
\mathrm{Ye} \\
\mathrm{s} \\
\mathrm{Ye} \\
\mathrm{s} \\
\mathrm{Ye} \\
\mathrm{s}\end{array}$ & $\begin{array}{l}7 \\
\text { Cormi } \\
\text { bidity: } \\
4 \text { No } \\
\text { corm } \\
\text { obitiy }\end{array}$ & $\begin{array}{l}11- \\
\text { mild }\end{array}$ & $\begin{array}{l}\text { D2 } \\
\text { D18 } \\
\text { D3 } \\
\text { D1 } \\
\text { D16 } \\
\text { D38, } \\
44 \\
\text { D3 } \\
\text { D6 } \\
\text { D7 } \\
\text { D6 } \\
\text { D11 }\end{array}$ & $\begin{array}{l}\mathrm{RT} \\
\mathrm{PC} \\
\mathrm{R}\end{array}$ & $\begin{array}{l}\text { Avl for } \\
9 \\
\text { patient } \\
\mathrm{s} 5 \\
\text { were } \\
\text { positiv } \\
\text { e, one } \\
\text { slightly } \\
\text { positiv } \\
\text { e and } \\
\text { three } \\
\text { negati } \\
\text { ves } \\
\text { (recd } \\
\text { chemo } \\
\text { therap } \\
\text { y and } \\
\text { rituxim } \\
\text { ab }\end{array}$ & NM & $\begin{array}{l}\text { Yes } \\
\text { Yes } \\
\text { Yes } \\
\text { Yes } \\
\text { Yes } \\
\text { Yes } \\
\text { Yes } \\
\text { Yes } \\
\text { Yes } \\
\text { Yes } \\
\text { Yes }\end{array}$ & $\begin{array}{l}\text { D29, } \\
\text { D36, } \\
55 \\
\text { D28 } \\
\text { D38 } \\
\text { D46 } \\
\text { D45 } \\
\text { D26 } \\
\text { D31 } \\
\text { D23, } \\
32, \\
36 \\
\text { D35 } \\
\text { D50 }\end{array}$ & $\begin{array}{l}\text { RT } \\
\text { PCR }\end{array}$ & $\begin{array}{l}3 \\
\text { Dead } \\
\text { and } \\
8 \\
\text { recov } \\
\text { ered }\end{array}$ \\
\hline 2 & $\begin{array}{l}\text { Lafai } \\
\text { et al } \\
1 \\
2 \\
3\end{array}$ & $\begin{array}{l}84, \\
F \\
90, \\
F \\
84, \\
F\end{array}$ & $\begin{array}{l}\text { Fran } \\
\text { ce }\end{array}$ & $\begin{array}{l}\text { Ye } \\
\text { s } \\
\text { Ye } \\
\text { s } \\
\text { Ye } \\
\mathrm{s}\end{array}$ & $\begin{array}{l}\text { Yes } \\
\text { Yes } \\
\text { Yes }\end{array}$ & $\begin{array}{l}\text { Sev } \\
-3\end{array}$ & $\begin{array}{l}26 \\
\text { Mar } \\
05 \\
\text { Apr } \\
15 \\
\text { Apr }\end{array}$ & $\begin{array}{l}P C \\
R \\
P C \\
R \\
P C \\
P C \\
R^{*} \\
\text { (ne } \\
g \text { ) }\end{array}$ & $\begin{array}{l}\text { Yes } \\
\text { No } \\
\text { Yes }\end{array}$ & $\begin{array}{l}\text { No } \\
\text { No } \\
\text { Yes }\end{array}$ & $\begin{array}{l}\text { Yes } \\
\text { Yes } \\
\text { Yes }\end{array}$ & $\begin{array}{l}26 \\
\text { days } \\
15 \\
\text { days } \\
11 \\
\text { days }\end{array}$ & $\begin{array}{l}\text { RT } \\
\text { PCR } \\
\text { RT } \\
\text { PCR } \\
\text { RT } \\
\text { PCR }\end{array}$ & $\begin{array}{l}\text { Deat } \\
\text { h } \\
\text { Deat } \\
\text { h } \\
\text { Deat } \\
\text { h }\end{array}$ \\
\hline 3 & $\begin{array}{l}\text { Enrico } \\
\text { et al }\end{array}$ & $\begin{array}{l}69, \\
F\end{array}$ & Italy & $\begin{array}{l}\text { Ye } \\
\mathrm{s}\end{array}$ & Yes & Mild & $\begin{array}{l}24 \\
\text { Mar }\end{array}$ & $\begin{array}{l}\mathrm{PC} \\
\mathrm{R}\end{array}$ & $\begin{array}{l}\text { Yes } \\
\text { IgG }\end{array}$ & $\begin{array}{l}\text { Yes } \\
\text { (tw }\end{array}$ & Yes & $\begin{array}{l}32 \\
\text { days }\end{array}$ & $\begin{array}{l}\text { RT } \\
\text { PCR }\end{array}$ & $\begin{array}{l}\text { Disc } \\
\text { harg }\end{array}$ \\
\hline
\end{tabular}


medRxiv preprint doi: https://doi.org/10.1101/2020.12.10.20223990; this version posted December 11, 2020. The copyright holder for this preprint (which was not certified by peer review) is the author/funder, who has granted medRxiv a license to display the preprint in perpetuity.

It is made available under a CC-BY-NC 4.0 International license .

\begin{tabular}{|c|c|c|c|c|c|c|c|c|c|c|c|c|c|c|}
\hline & & & & & & & & & $\begin{array}{l}\text { Positiv } \\
\text { e }\end{array}$ & o) & & & & ed \\
\hline 4 & $\begin{array}{ll}\text { Ye } & \text { et } \\
\text { al } & \\
1 & \\
2 & \\
3 & \\
4 & \\
5 & \end{array}$ & $\begin{array}{l}30, \\
M \\
42, \\
M \\
32, \\
F \\
27, \\
F \\
31, \\
F\end{array}$ & $\begin{array}{l}\text { Chin } \\
\mathrm{a}\end{array}$ & $\begin{array}{l}\text { Ye } \\
\text { s } \\
\text { Ye } \\
\text { s } \\
\text { Ye } \\
\text { s } \\
\text { No } \\
\text { Ye } \\
\mathrm{s}\end{array}$ & $\begin{array}{l}\text { No } \\
\text { No } \\
\text { No } \\
\text { No } \\
\text { No }\end{array}$ & $\begin{array}{l}\text { Mild } \\
\text { Mild } \\
\text { Mild } \\
\text { Mild } \\
\text { Mild }\end{array}$ & NM & NM & NM & $\begin{array}{l}\text { Yes } \\
\text { Yes } \\
\text { Yes } \\
\text { Yes } \\
\text { Yes }\end{array}$ & NM & $\begin{array}{l}N G \\
(4- \\
17 \\
\text { days } \\
\text { after } \\
\text { nega } \\
\text { tive } \\
\text { test) }\end{array}$ & $\begin{array}{l}\text { RT } \\
\text { PCR } \\
\text { RT } \\
\text { PCR } \\
\text { RT } \\
\text { PCR } \\
\text { RT } \\
\text { PCR } \\
\text { RT } \\
\text { PCR }\end{array}$ & $\begin{array}{l}\text { Stabl } \\
\text { e } \\
\text { Stabl } \\
\text { e } \\
\text { Stabl } \\
\text { e } \\
\text { Stabl } \\
\text { e } \\
\text { Stabl } \\
\text { e }\end{array}$ \\
\hline 5 & $\begin{array}{l}\text { Ravioli } \\
\text { et al } \\
1 \\
2\end{array}$ & $\begin{array}{l}81, \\
F \\
77, \\
F\end{array}$ & $\begin{array}{l}\text { Switz } \\
\text { erlan } \\
\text { d }\end{array}$ & $\begin{array}{l}\text { Ye } \\
\mathrm{s} \\
\mathrm{Ye} \\
\mathrm{s}\end{array}$ & $\begin{array}{l}\text { Yes } \\
\text { Yes }\end{array}$ & $\begin{array}{l}\text { Mod } \\
\text { erat } \\
\text { e }\end{array}$ & $\begin{array}{l}09 \\
\text { Mar } \\
23 \\
\text { Mar }\end{array}$ & $\begin{array}{l}P C \\
R \\
P C \\
R\end{array}$ & $\begin{array}{l}\text { NM } \\
\text { NM }\end{array}$ & $\begin{array}{l}\text { Yes } \\
\text { Yes }\end{array}$ & $\begin{array}{l}\text { Yes } \\
\text { Yes }\end{array}$ & $\begin{array}{l}21 \\
14\end{array}$ & $\begin{array}{l}\text { RT } \\
\text { PCR } \\
\text { RT } \\
\text { PCR }\end{array}$ & $\begin{array}{l}\text { Died } \\
\text { Stabl } \\
\text { e }\end{array}$ \\
\hline 6 & $\begin{array}{l}\text { Locons } \\
\text { ole et } \\
\text { al }\end{array}$ & $\begin{array}{l}48, \\
M\end{array}$ & Italy & $\begin{array}{l}\text { Ye } \\
\mathrm{s}\end{array}$ & No & $\begin{array}{l}\text { Sev } \\
\text { ere }\end{array}$ & $\begin{array}{l}17 \\
\text { Mar }\end{array}$ & $\begin{array}{l}\mathrm{PC} \\
\mathrm{R}\end{array}$ & Yes & Yes & Yes & 30 & $\begin{array}{l}\text { RT } \\
\text { PCR }\end{array}$ & $\begin{array}{l}\text { Stabl } \\
\mathrm{e}\end{array}$ \\
\hline 7 & $\begin{array}{l}\text { Jiang } \\
\text { et al(6) } \\
1 \\
2 \\
3 \\
4 \\
5 \\
6\end{array}$ & $\begin{array}{l}35 \mathrm{~F} \\
56 \mathrm{~F} \\
\mathrm{~F} \\
\mathrm{~F} \\
\mathrm{~F} \\
\mathrm{~F}\end{array}$ & $\begin{array}{l}\text { Chin } \\
\text { a }\end{array}$ & $\begin{array}{l}Y e \\
\mathrm{~s} \\
\mathrm{Ye} \\
\mathrm{s} \\
\mathrm{Ye} \\
\mathrm{s} \\
\mathrm{Ye} \\
\mathrm{s} \\
\mathrm{Ye} \\
\mathrm{s} \\
\mathrm{Ye} \\
\mathrm{s} \\
\end{array}$ & $\begin{array}{l}\text { No } \\
\text { Yes } \\
\text { No } \\
\text { No } \\
\text { Yes } \\
\text { No }\end{array}$ & Mild & $\begin{array}{l}30 \\
\text { Jan } \\
30 \\
\text { Jan } \\
03 \\
\text { Feb } \\
03 \\
\text { Feb } \\
05 \\
\text { Feb } \\
06 \\
\text { Feb }\end{array}$ & $\begin{array}{l}P C \\
R \\
P C \\
R \\
P C \\
R \\
P C \\
R \\
P C \\
R \\
R \\
P C \\
R\end{array}$ & $\begin{array}{l}\text { No } \\
\text { No } \\
\text { No } \\
\text { No } \\
\text { No } \\
\text { No }\end{array}$ & $\begin{array}{l}\text { Yes } \\
\text { Yes } \\
\text { Yes } \\
\text { Yes } \\
\text { Yes } \\
\text { Yes }\end{array}$ & $\begin{array}{l}\text { Yes } \\
\text { No } \\
\text { Yes } \\
\text { No } \\
\text { No } \\
\text { No }\end{array}$ & $\begin{array}{l}9 \\
\text { days } \\
14 \\
\text { days } \\
8 \\
\text { days } \\
7 \\
\text { days } \\
9 \\
\text { days } \\
5 \\
\text { days }\end{array}$ & $\begin{array}{l}\text { PCR } \\
\text { PCR } \\
\text { PCR } \\
\text { PCR } \\
\text { PCR } \\
\text { PCR }\end{array}$ & $\begin{array}{l}\text { Re- } \\
\text { hosp } \\
\text { Stabl } \\
\text { e } \\
\text { Stabl } \\
\text { e } \\
\text { Stabl } \\
\text { e } \\
\text { Alive } \\
\text { Alive }\end{array}$ \\
\hline 8 & $\begin{array}{l}\text { Chang } \\
\text { et al(7) } \\
1 \\
2 \\
3 \\
4 \\
5 \\
6 \\
7\end{array}$ & $\begin{array}{l}14 \mathrm{M} \\
13 \mathrm{M} \\
10 \\
\text { (mo } \\
\text { nths) } \\
\mathrm{F} \\
35 \mathrm{M} \\
35 \mathrm{M} \\
33 \mathrm{M} \\
26 \mathrm{M}\end{array}$ & $\begin{array}{l}\text { Chin } \\
\text { a }\end{array}$ & $\begin{array}{l}\text { No } \\
\text { No } \\
\text { Ye } \\
\text { s } \\
\text { Ye } \\
\text { s } \\
\text { No } \\
\text { No } \\
\text { Ye } \\
\text { s }\end{array}$ & $\begin{array}{l}\text { No } \\
\text { No } \\
\text { No } \\
\text { No } \\
\text { No } \\
\text { No } \\
\text { No }\end{array}$ & $\begin{array}{l}\text { Mild } \\
-6 \\
\text { Mod } \\
\text { erat } \\
\text { e }-1\end{array}$ & $\begin{array}{l}01 \\
\text { Feb } \\
01 \\
\text { Feb } \\
05 \\
\text { Feb } \\
02 \\
\text { Feb } \\
31 \\
\text { Jan } \\
27 \\
\text { Jan } \\
26 \\
\text { Jan }\end{array}$ & $\begin{array}{l}P C \\
R \\
P C \\
R \\
P C \\
R \\
P C \\
R \\
P C \\
R \\
P C \\
R \\
P C \\
R\end{array}$ & $\begin{array}{l}\text { No } \\
\text { No } \\
\text { No } \\
\text { No } \\
\text { No } \\
\text { No } \\
\text { No }\end{array}$ & $\begin{array}{l}\text { Yes } \\
\text { Yes } \\
\text { Yes } \\
\text { Yes } \\
\text { Yes } \\
\text { Yes } \\
\text { yes }\end{array}$ & $\begin{array}{l}\text { No } \\
\text { No } \\
\text { No } \\
\text { No } \\
\text { No } \\
\text { No } \\
\text { No }\end{array}$ & $\begin{array}{l}7 \\
11 \\
9 \\
9 \\
8 \\
5 \\
11\end{array}$ & $\begin{array}{l}4 R S \\
2 P C R \\
1 P C R \\
\text { and } 1 \\
\text { Rs }\end{array}$ & $\begin{array}{l}\text { Alive } \\
\text { Alive } \\
\text { Alive } \\
\text { Alive } \\
\text { Alive } \\
\text { Alive } \\
\text { Alive }\end{array}$ \\
\hline 9 & $\begin{array}{l}\text { Yoo et } \\
\text { al }\end{array}$ & $8 \mathrm{M}$ & $\begin{array}{l}\text { Kore } \\
\mathrm{a}\end{array}$ & $\begin{array}{l}\text { Ye } \\
\mathrm{s}\end{array}$ & No & Mild & $\begin{array}{l}03 \\
\text { Mar }\end{array}$ & $\begin{array}{l}\mathrm{PC} \\
\mathrm{R}\end{array}$ & No & Yes & Yes & 14 & PCR & Alive \\
\hline $\begin{array}{l}1 \\
0\end{array}$ & $\begin{array}{l}\text { Liu et } \\
\text { al }\end{array}$ & $35 \mathrm{M}$ & $\begin{array}{l}\text { Chin } \\
\mathrm{a}\end{array}$ & yes & No & Mild & $\begin{array}{l}30 \\
\text { Jan }\end{array}$ & $\begin{array}{l}\mathrm{PC} \\
\mathrm{R}\end{array}$ & Yes & Yes & Yes & 15 & PCR & Alive \\
\hline $\begin{array}{l}1 \\
1\end{array}$ & $\begin{array}{l}\text { Yuan } \\
\text { et al } \\
(20 / 18\end{array}$ & $38 \mathrm{M}$ & Chin & & & $\begin{array}{l}\text { Mild } \\
\text { to }\end{array}$ & NM & PC & $\begin{array}{l}14 \\
\text { were } \\
\text { tested }\end{array}$ & Yes & 20 -No & 13- & 14 & Stabl \\
\hline
\end{tabular}


medRxiv preprint doi: https://doi.org/10.1101/2020.12.10.20223990; this version posted December 11 , 2020. The copyright holder for this preprint (which was not certified by peer review) is the author/funder, who has granted medRxiv a license to display the preprint in perpetuity.

It is made available under a CC-BY-NC 4.0 International license .

\begin{tabular}{|c|c|c|c|c|c|c|c|c|c|c|c|c|c|c|}
\hline & $\begin{array}{l}2) \\
1 \\
2 \\
3 \\
4 \\
5 \\
6 \\
7 \\
8 \\
9 \\
10 \\
11 \\
12 \\
13 \\
14 \\
15 \\
16 \\
17 \\
18 \\
19 \\
20 \\
\end{array}$ & $\begin{array}{l}53 \mathrm{M} \\
40 \mathrm{~F} \\
61 \mathrm{~F} \\
64 \mathrm{~F} \\
53 \mathrm{~F} \\
33 \mathrm{~F} \\
1 \mathrm{~F} \\
34 \mathrm{~F} \\
43 \mathrm{M} \\
34 \mathrm{~F} \\
38 \mathrm{M} \\
50 \mathrm{~F} \\
50 \mathrm{~F} \\
5 \mathrm{~F} \\
55 \mathrm{~F} \\
72 \mathrm{~F} \\
54 \mathrm{M} \\
8 \mathrm{M} \\
12 \mathrm{M}\end{array}$ & $a$ & $\begin{array}{l}19- \\
Y e \\
\mathrm{~s} \\
1- \\
\text { No }\end{array}$ & $\begin{array}{l}6 \\
\text { peopl } \\
\text { e had } \\
\text { comm } \\
\text { oditie } \\
\text { s }\end{array}$ & $\begin{array}{l}\text { mod } \\
\text { erat } \\
\text { e }\end{array}$ & & $R$ & $\begin{array}{l}\text { and } \\
\text { all of } \\
\text { them } \\
\text { have } \\
\text { antibo } \\
\text { dies }\end{array}$ & & & $\begin{array}{l}\text { retes } \\
\text { ted } \\
\text { at } 07 \\
\text { days } \\
7 \\
\text { retes } \\
\text { ted } \\
14 \\
\text { days }\end{array}$ & $\begin{array}{l}\text { nasoph } \\
\text { arynge } \\
\text { al and } \\
7 \text { anal } \\
\text { swabs }\end{array}$ & e \\
\hline $\begin{array}{l}1 \\
2\end{array}$ & $\begin{array}{l}\text { Lan et } \\
\text { al } \\
1 \\
2 \\
3 \\
4\end{array}$ & $\begin{array}{l}30- \\
36,2 \\
M\end{array}$ & $\begin{array}{l}\text { Chin } \\
\text { a }\end{array}$ & $\begin{array}{l}\text { 3- } \\
\text { sy } \\
\mathrm{mp} \\
1- \\
\text { asy } \\
\mathrm{mp}\end{array}$ & NM & $\begin{array}{l}\text { Mild } \\
\text { to } \\
\text { mod } \\
\text { erat } \\
\text { e }\end{array}$ & NM & $\begin{array}{l}\mathrm{PC} \\
\mathrm{R}\end{array}$ & NM & Yes & aymp & $\begin{array}{l}5-13 \\
\text { days } \\
\text { after } \\
\text { disc } \\
\text { hage }\end{array}$ & PCR & Alive \\
\hline $\begin{array}{l}1 \\
3\end{array}$ & $\begin{array}{l}\text { Cao et } \\
\text { al } \\
1 \\
2 \\
3 \\
4 \\
5 \\
6 \\
7 \\
8\end{array}$ & $\begin{array}{l}54 \mathrm{~F} \\
72 \mathrm{~F} \\
60 \mathrm{~F} \\
65 \mathrm{~F} \\
58 \mathrm{M} \\
64 \mathrm{M} \\
36 \mathrm{~F} \\
26 \mathrm{M}\end{array}$ & $\begin{array}{l}\text { Chin } \\
\text { a }\end{array}$ & $\begin{array}{l}\text { Sy } \\
\text { m } \\
\text { Sy } \\
\text { m } \\
\text { Sy } \\
\text { m } \\
\text { Sy } \\
\text { m } \\
\text { Sy } \\
\text { m } \\
\text { Sy } \\
\text { m } \\
\text { Sy } \\
\text { m } \\
\text { As } \\
\text { ym }\end{array}$ & $\begin{array}{l}\text { No } \\
\text { No } \\
\text { No } \\
\text { Hypot } \\
\text { h } \\
\text { No } \\
\text { No } \\
\text { No } \\
\text { No }\end{array}$ & $\begin{array}{l}\text { Sev } \\
\text { ere } \\
\text { Mod } \\
\text { erat } \\
\text { e } \\
\text { Mod } \\
\text { erat } \\
\text { e } \\
\text { Mod } \\
\text { erat } \\
\text { e } \\
\text { Mod } \\
\text { erat } \\
\text { e } \\
\text { Sev } \\
\text { ere } \\
\text { Mod } \\
\text { erat } \\
\text { e } \\
\text { Mod } \\
\text { erat } \\
\text { e }\end{array}$ & NM & $\begin{array}{l}\mathrm{PC} \\
\mathrm{R}\end{array}$ & NM & $\begin{array}{l}\text { Yes } \\
\text { Yes } \\
\text { Yes } \\
\text { Yes } \\
\text { Yes } \\
\text { Yes } \\
\text { Yes } \\
\text { Yes }\end{array}$ & $\begin{array}{l}\text { Asym } \\
\text { Asym } \\
\text { Asym } \\
\text { Asym } \\
\text { Asym } \\
\text { Asym } \\
\text { Asym } \\
\text { Asym }\end{array}$ & $\begin{array}{l}12 \\
14 \\
09 \\
12 \\
16 \\
29 \\
06 \\
06\end{array}$ & PCR & Alive \\
\hline $\begin{array}{l}1 \\
4\end{array}$ & $\begin{array}{l}\text { Deng } \\
\text { et al } \\
576 \\
\text { (conta } \\
\text { ct were } \\
\text { negativ } \\
\text { e) }\end{array}$ & $\begin{array}{l}61 / 5 \\
76 \\
(10 . \\
6 \%) \\
\text { Age } \\
- \\
54.8 \\
\text { year } \\
\text { s, } 36 \\
\text { F }\end{array}$ & $\begin{array}{l}\text { Chin } \\
\text { a }\end{array}$ & NM & $\begin{array}{l}24 \\
(39.3 \\
\%)\end{array}$ & $\begin{array}{l}\text { Sev } \\
\text { ere } \\
3 \\
(4.9 \\
\%)\end{array}$ & NM & $\begin{array}{l}\mathrm{PC} \\
\mathrm{R}\end{array}$ & $\begin{array}{l}\text { Not } \\
\text { done }\end{array}$ & Yes & $\begin{array}{l}38 \\
\text { asymp } \\
\text { (Mild } \\
\text { status) }\end{array}$ & $\begin{array}{l}0(7- \\
13)\end{array}$ & $\begin{array}{l}\text { 36PCR } \\
: \quad 17 \\
\text { stools; } \\
8 \\
\text { sputum }\end{array}$ & Alive \\
\hline
\end{tabular}


medRxiv preprint doi: https://doi.org/10.1101/2020.12.10.20223990; this version posted December 11,2020 . The copyright holder for this preprint (which was not certified by peer review) is the author/funder, who has granted medRxiv a license to display the preprint in perpetuity.

It is made available under a CC-BY-NC 4.0 International license .

\begin{tabular}{|c|c|c|c|c|c|c|c|c|c|c|c|c|c|c|}
\hline & & $\begin{array}{l}(23 \\
\text { were } \\
\text { adm } \\
\text { antiv } \\
\text { iral) }\end{array}$ & & & & & & & & & & & & \\
\hline $\begin{array}{l}1 \\
5\end{array}$ & $\begin{array}{l}\text { Peng } \\
\text { et al } \\
1 \\
2 \\
3 \\
4 \\
5 \\
6 \\
7\end{array}$ & $\begin{array}{l}67 M \\
-M \\
-F \\
-M \\
38 F \\
29 M \\
21 F\end{array}$ & $\begin{array}{l}\text { Chin } \\
\mathrm{a}\end{array}$ & $\begin{array}{l}\text { Sy } \\
\text { m } \\
\text { Sy } \\
\text { m } \\
\text { Sy } \\
\text { m } \\
\text { Sy } \\
\text { m } \\
\text { Sy } \\
\text { m } \\
\text { Sy } \\
\text { m } \\
\text { Sy } \\
\text { m }\end{array}$ & $\begin{array}{l}\text { NM } \\
\text { NM } \\
\text { NM } \\
\text { NM } \\
\text { NM } \\
\text { NM } \\
\text { NM }\end{array}$ & $\begin{array}{l}\text { Mild } \\
\text { Mild } \\
\text { Mild } \\
\text { Mild } \\
\text { Mild } \\
\text { Mild } \\
\text { Mild }\end{array}$ & $\begin{array}{l}24 \\
\text { Jan } \\
24 \\
\text { Jan } \\
27 \\
\text { Jan } \\
28 \\
\text { Jan } \\
24 \\
\text { Jan } \\
29 \\
\text { Jan } \\
31 \\
\text { Jan }\end{array}$ & $\begin{array}{l}P C \\
R \\
P C \\
R \\
P C \\
R \\
P C \\
R \\
P C \\
R \\
P C \\
R \\
P C \\
R\end{array}$ & $\begin{array}{l}\text { NM } \\
\text { NM } \\
\text { NM } \\
\text { NM } \\
\text { NM } \\
\text { NM } \\
\text { NM }\end{array}$ & $\begin{array}{l}\text { Yes } \\
\text { Yes } \\
\text { Yes } \\
\text { Yes } \\
\text { Yes } \\
\text { Yes } \\
\text { Yes }\end{array}$ & $\begin{array}{l}\text { Asym } \\
\text { Asym } \\
\text { Asym } \\
\text { Asym } \\
\text { Asym } \\
\text { Asym } \\
\text { Asym }\end{array}$ & $\begin{array}{l}4 \\
6 \\
3 \\
7 \\
6 \\
6 \\
5\end{array}$ & $\begin{array}{l}\text { PCR } \\
\text { PCR } \\
\text { PCR } \\
\text { PCR } \\
\text { AS } \\
\text { AS } \\
\text { PCR }\end{array}$ & $\begin{array}{l}\text { Alive } \\
\text { Alive } \\
\text { Alive } \\
\text { Alive } \\
\text { Alive } \\
\text { Alive } \\
\text { Alive }\end{array}$ \\
\hline $\begin{array}{l}1 \\
6\end{array}$ & $\begin{array}{l}\text { Wu et } \\
\text { al } \\
\text { No } \\
\text { contact } \\
\text { s } \\
1 \\
2 \\
3 \\
4 \\
5 \\
6 \\
7 \\
8 \\
9 \\
10\end{array}$ & $\begin{array}{l}>70 \\
>70 \\
\text { NM } \\
\text { NM } \\
\text { NM } \\
\text { NM } \\
\text { NM } \\
\text { NM } \\
\text { NM } \\
\text { NM }\end{array}$ & $\begin{array}{l}\text { Chin } \\
\mathrm{a}\end{array}$ & $\begin{array}{l}\text { NM } \\
\text { NM } \\
\text { NM } \\
\text { NM } \\
\text { NM } \\
\text { NM } \\
\text { NM } \\
\text { NM } \\
\text { NM } \\
\text { NM }\end{array}$ & $\begin{array}{l}\text { Yes } \\
\text { Yes } \\
\text { NM } \\
\text { NM } \\
\text { NM } \\
\text { NM } \\
\text { NM } \\
\text { NM } \\
\text { NM } \\
\text { NM }\end{array}$ & $\begin{array}{l}\text { NM } \\
\text { NM } \\
\text { NM } \\
\text { NM } \\
\text { NM } \\
\text { NM } \\
\text { NM } \\
\text { NM } \\
\text { NM } \\
\text { NM }\end{array}$ & $\begin{array}{l}01 \mathrm{Fe} \\
\text { b } \\
02 \mathrm{Fe} \\
b^{\prime} \\
02 \mathrm{Fe} \\
\mathrm{b} \\
23 \mathrm{Ja} \\
\mathrm{n} \\
27 \mathrm{Ja} \\
\mathrm{n} \\
30 \mathrm{Ja} \\
\mathrm{n} \\
29 \mathrm{Ja} \\
\mathrm{n} \\
28 \mathrm{Ja} \\
\mathrm{n} \\
07 \mathrm{Fe} \\
\mathrm{b} \\
07 \mathrm{Fe} \\
\mathrm{b}\end{array}$ & $\begin{array}{l}\text { NM } \\
\text { NM } \\
\text { NM } \\
\text { NM } \\
\text { NM } \\
\text { NM } \\
\text { NM } \\
\text { NM } \\
\text { NM } \\
\text { NM }\end{array}$ & $\begin{array}{l}\text { NM } \\
\text { NM } \\
\text { NM } \\
\text { NM } \\
\text { NM } \\
\text { NM } \\
\text { NM } \\
\text { NM } \\
\text { NM } \\
\text { NM }\end{array}$ & $\begin{array}{l}\text { NM } \\
\text { NM } \\
\text { NM } \\
\text { NM } \\
\text { NM } \\
\text { NM } \\
\text { NM } \\
\text { NM } \\
\text { NM } \\
\text { NM }\end{array}$ & $\begin{array}{l}\text { Symp } \\
\text { Symp } \\
\text { Asym } \\
p \\
\text { Asym } \\
p \\
\text { Asym } \\
p \\
\text { Asym } \\
p \\
\text { Asym } \\
p \\
\text { Asym } \\
p \\
\text { Asym } \\
p \\
\text { Asym } \\
p\end{array}$ & $\begin{array}{l}3 \\
5 \\
6 \\
25 \\
16 \\
9 \\
22 \\
23 \\
11 \\
07\end{array}$ & $\begin{array}{l}P \\
P A \\
A \\
P \\
P \\
P \\
A \\
A \\
A \\
A\end{array}$ & $\begin{array}{l}\text { Alive } \\
\text { Alive } \\
\text { Alive } \\
\text { Alive } \\
\text { Alive } \\
\text { Alive } \\
\text { Alive } \\
\text { Alive } \\
\text { Alive } \\
\text { Alive }\end{array}$ \\
\hline $\begin{array}{l}1 \\
7\end{array}$ & $\begin{array}{l}\text { Zhou } \\
\text { et } \\
\text { al(11) } \\
\text { (antivir } \\
\text { al) }\end{array}$ & $40 M$ & $\begin{array}{l}\text { Chin } \\
\mathrm{a}\end{array}$ & $\begin{array}{l}\text { Sy } \\
\text { m }\end{array}$ & $\begin{array}{l}\text { B cell } \\
\text { defici } \\
\text { ency }\end{array}$ & $\begin{array}{l}\text { Sev } \\
\text { ere }\end{array}$ & $\begin{array}{l}\text { 23Ja } \\
\mathrm{n}\end{array}$ & $\begin{array}{l}\mathrm{PC} \\
\mathrm{R}\end{array}$ & $\begin{array}{l}\text { YES } 9 \\
\text { Day } \\
31 \text { and } \\
\text { day } \\
33 \text { ) } \\
\text { lower } \\
\text { level } \\
\text { of } \\
\text { antibo } \\
\text { dy }\end{array}$ & $\begin{array}{l}\text { YE } \\
S\end{array}$ & $\begin{array}{l}\text { YES } \\
5\end{array}$ & $\begin{array}{l}5 \\
\text { days } \\
\text { after } \\
\text { disc } \\
\text { harg } \\
\text { e }\end{array}$ & PCR & Alive \\
\hline $\begin{array}{l}1 \\
8\end{array}$ & $\begin{array}{l}\text { Zhao } \\
\text { et al } \\
(12) \\
(7 / 14) \\
\text { Secon } \\
d \\
\text { reactiv } \\
\text { ation in } \\
2\end{array}$ & $\begin{array}{l}5.7 \\
(2.9- \\
7.3) r \\
4 \mathrm{~F}\end{array}$ & $\begin{array}{l}\text { Chin } \\
\mathrm{a}\end{array}$ & $\begin{array}{l}5 \\
\text { sy } \\
\mathrm{mp} \\
\text { to } \\
\text { an } \\
\mathrm{d} 2 \\
\text { asy } \\
\mathrm{mp}\end{array}$ & $\begin{array}{l}\text { No } \\
\text { Co- } \\
\text { morbi } \\
\text { dity }\end{array}$ & Mild & NM & $\begin{array}{l}\mathrm{PC} \\
\mathrm{R}\end{array}$ & NM & Yes & $\begin{array}{l}6 \\
\text { asymp } \\
1 \\
\text { symp }\end{array}$ & $\begin{array}{l}14 \\
\text { days } \\
\text { from } \\
\text { disc } \\
\text { harg } \\
\text { e (7- } \\
17)\end{array}$ & PCR & Alive \\
\hline 1 & Li et al & $50 \mathrm{M}$ & Chin & Sy & Yes & Mild & D13 & $\mathrm{PC}$ & Yes & yes & Aymp & 14 & PCR & Alive \\
\hline
\end{tabular}


medRxiv preprint doi: https://doi.org/10.1101/2020.12.10.20223990; this version posted December 11, 2020. The copyright holder for this preprint (which was not certified by peer review) is the author/funder, who has granted medRxiv a license to display the preprint in perpetuity.

It is made available under a CC-BY-NC 4.0 International license .

\begin{tabular}{|c|c|c|c|c|c|c|c|c|c|c|c|c|c|c|}
\hline 9 & (13) & & $a$ & $\mathrm{~m}$ & & & & $\mathrm{R}$ & $\begin{array}{l}\text { on } D \\
40 . \\
\text { IgM } \\
\text { and } \\
\text { IgG } \\
\text { positiv } \\
\text { e }\end{array}$ & & & & & \\
\hline $\begin{array}{l}2 \\
0\end{array}$ & \begin{tabular}{l}
\multicolumn{3}{l}{ Chen } \\
et al al \\
$(14)$ \\
1 \\
2 \\
3 \\
4
\end{tabular} & $\begin{array}{l}29 \mathrm{M} \\
49 \mathrm{~F} \\
12 \mathrm{~F} \\
38 \mathrm{M}\end{array}$ & $\begin{array}{l}\text { Chin } \\
\text { a }\end{array}$ & $\begin{array}{l}\text { Sy } \\
\mathrm{mp} \\
\text { Sy } \\
\mathrm{mp} \\
\text { Ay } \\
\mathrm{mp} \\
\text { sy } \\
\mathrm{mp}\end{array}$ & $\begin{array}{l}\text { NK } \\
\text { NK } \\
\text { NK } \\
\text { Nk }\end{array}$ & $\begin{array}{l}\text { Mild } \\
\text { Mild } \\
\text { Mild } \\
\text { mild }\end{array}$ & $\begin{array}{l}01 \\
\text { Feb } \\
02 \\
\text { Feb } \\
05 \\
\text { Feb } \\
30 \\
\text { Jan }\end{array}$ & $\begin{array}{l}\mathrm{PC} \\
\mathrm{R}\end{array}$ & $\begin{array}{l}\text { NM } \\
\text { NM } \\
\text { NM } \\
\text { NM }\end{array}$ & $\begin{array}{l}\text { Yes } \\
\text { Yes } \\
\text { Yes } \\
\text { Yes }\end{array}$ & $\begin{array}{l}\text { Asym } \\
\mathrm{p} \\
\text { Asym } \\
\text { Asym } \\
\text { Asym }\end{array}$ & $\begin{array}{l}3 \\
3 \\
3 \\
3\end{array}$ & PCR & Alive \\
\hline $\begin{array}{l}2 \\
1\end{array}$ & $\begin{array}{l}\mathrm{Hu} \text { et } \\
\text { al } \\
(11 / 69) \\
33 y e a r \\
\text { s (2-78 } \\
\text { years) } \\
(15)\end{array}$ & $\begin{array}{l}11 \\
\text { medi } \\
\text { an } \\
\text { age } \\
27, \\
\text { rang } \\
\text { e } 4- \\
58 \\
\text { year } \\
\text { S } \\
4 \mathrm{~F}\end{array}$ & $\begin{array}{l}\text { Chin } \\
\mathrm{a}\end{array}$ & $\begin{array}{l}9- \\
\text { mo } \\
d \\
1- \\
\text { mil } \\
d \\
1- \\
\text { criti } \\
\text { cal }\end{array}$ & $\begin{array}{l}3 \\
\text { patie } \\
\text { nts }\end{array}$ & $\begin{array}{l}\text { Mild } \\
1 \\
\text { Mod } \\
9 \\
\text { Sev } \\
\text { ere } \\
1\end{array}$ & NM & $\begin{array}{l}\mathrm{PC} \\
\mathrm{R}\end{array}$ & NM & Yes & $\begin{array}{l}\text { Asym } \\
\mathrm{p}\end{array}$ & $\begin{array}{l}14 \\
(9- \\
17)\end{array}$ & PCR & Alive \\
\hline $\begin{array}{l}2 \\
2\end{array}$ & $\begin{array}{l}\text { Jiangh } \\
\text { ong An } \\
\text { et al ( } \\
\mathrm{n}= \\
262) \\
\text { Mild - } \\
30 \\
\text { Mod } \\
212 \\
\text { Severe } \\
20\end{array}$ & $\begin{array}{l}\text { Medi } \\
\text { dan } \\
\text { age } \\
20 \\
(5- \\
64) \\
7 \mathrm{~F} \\
38 \\
(2- \\
60) \\
15 \mathrm{~F}\end{array}$ & $\begin{array}{l}\text { Chin } \\
\mathrm{a}\end{array}$ & $\begin{array}{l}\text { Ye } \\
\mathrm{s}\end{array}$ & $\begin{array}{l}1 / 11 \\
1 / 27\end{array}$ & $\begin{array}{l}\text { Mild } \\
-11 \\
\text { Mod } \\
\text { erat } \\
\text { e } 27\end{array}$ & $\begin{array}{l}\text { Patie } \\
\text { nt } \\
\text { were } \\
\text { disch } \\
\text { arge } \\
\text { d, } \\
\text { Jan2 } \\
3 \text { to } \\
\text { Feb } \\
25 \\
\text { (14 } \\
\text { days) }\end{array}$ & $\begin{array}{l}\text { RT } \\
\text { PC } \\
\text { R, } \\
\text { An } \\
\text { al } \\
\text { sw } \\
\text { ab }\end{array}$ & $\begin{array}{l}\text { Yes } \\
\text { no } \\
\text { differe } \\
\text { nce } \\
\text { betwe } \\
\text { en the } \\
\text { two } \\
\text { groups }\end{array}$ & Yes & No & $\begin{array}{l}\text { Wee } \\
\text { kly } \\
\text { after } \\
\text { disc } \\
\text { harg } \\
\text { e }\end{array}$ & $\begin{array}{l}\text { RT } \\
\text { PCR }\end{array}$ & $\begin{array}{l}\text { Reco } \\
\text { vere } \\
\text { d }\end{array}$ \\
\hline $\begin{array}{l}2 \\
3\end{array}$ & $\begin{array}{l}\text { Chen } \\
\text { et al }\end{array}$ & $46 \mathrm{~F}$ & $\begin{array}{l}\text { Chin } \\
\mathrm{a}\end{array}$ & $\begin{array}{l}\text { Fe } \\
\text { ver }\end{array}$ & no & Mild & $\begin{array}{l}24 \\
\text { Jan }\end{array}$ & $\begin{array}{l}\text { RT } \\
\text { PC } \\
\text { R }\end{array}$ & No & Yes & No & $\begin{array}{l}03 \\
\text { days } \\
\text { after } \\
\text { last } \\
\text { nega } \\
\text { tive } \\
\text { test }\end{array}$ & $\begin{array}{l}\text { RT } \\
\text { PCR }\end{array}$ & $\begin{array}{l}\text { Reco } \\
\text { verd }\end{array}$ \\
\hline $\begin{array}{l}2 \\
4\end{array}$ & $\begin{array}{l}\text { Dugga } \\
\mathrm{n} \text { et al }\end{array}$ & $82 \mathrm{M}$ & USA & $\begin{array}{l}\text { Sy } \\
\mathrm{m}\end{array}$ & Yes & $\begin{array}{l}\text { Sev } \\
\text { ere }\end{array}$ & $\begin{array}{l}\text { Early } \\
\text { apr }\end{array}$ & $\begin{array}{l}\text { RT } \\
\text { PC } \\
\text { R }\end{array}$ & No & Yes & Asym & $\begin{array}{l}10 \\
\text { days } \\
\text { post } \\
\text { disc } \\
\text { harg } \\
\mathrm{e}\end{array}$ & $\begin{array}{l}\text { RT } \\
\text { PCR }\end{array}$ & $\begin{array}{l}\text { Disc } \\
\text { harg } \\
\text { ed }\end{array}$ \\
\hline $\begin{array}{l}2 \\
5\end{array}$ & $\begin{array}{l}\text { Ye-min } \\
\text { et al }\end{array}$ & $49 \mathrm{M}$ & $\begin{array}{l}\text { Chin } \\
\mathrm{a}\end{array}$ & $\begin{array}{l}\text { Sy } \\
\text { m }\end{array}$ & NM & mild & $\begin{array}{l}22 \\
\text { Jan }\end{array}$ & $\begin{array}{l}\text { RT } \\
\text { PC } \\
\text { R }\end{array}$ & NM & Yes & Asym & $\begin{array}{l}3 \\
\text { days } \\
\text { after } \\
\text { disc } \\
\text { harg } \\
\text { e }\end{array}$ & $\begin{array}{l}\text { Sputum } \\
\text { positive } \\
\text { PCR - } \\
\text { ve }\end{array}$ & $\begin{array}{l}\text { Disc } \\
\text { harg } \\
\text { ed }\end{array}$ \\
\hline $\begin{array}{l}2 \\
6\end{array}$ & $\begin{array}{l}\text { To et } \\
\text { al }\end{array}$ & $33 \mathrm{M}$ & $\begin{array}{l}\text { Hong } \\
\text { kong }\end{array}$ & $\begin{array}{l}\text { Sy } \\
\text { m }\end{array}$ & $\begin{array}{l}\text { No } \\
\text { Co- } \\
\text { morbi }\end{array}$ & Mild & $\begin{array}{l}29 \\
\text { Mar }\end{array}$ & $\begin{array}{l}\text { RT } \\
\text { PC } \\
\text { R }\end{array}$ & NM & Yes & $\begin{array}{l}\text { Asym } \\
\text { ptoma } \\
\text { tic }\end{array}$ & $\begin{array}{l}123 \\
\text { days } \\
\text { after }\end{array}$ & $\begin{array}{l}\text { RT } \\
\text { PCR }\end{array}$ & $\begin{array}{l}\text { Disc } \\
\text { harg } \\
\text { ed }\end{array}$ \\
\hline
\end{tabular}


medRxiv preprint doi: https://doi.org/10.1101/2020.12.10.20223990; this version posted December 11, 2020. The copyright holder for this preprint (which was not certified by peer review) is the author/funder, who has granted medRxiv a license to display the preprint in perpetuity.

It is made available under a CC-BY-NC 4.0 International license .

\begin{tabular}{|c|c|c|c|c|c|c|c|c|c|c|c|c|c|c|}
\hline & & & & & dity & & & & & & & $\begin{array}{l}\text { disc } \\
\text { harg } \\
\mathrm{e}\end{array}$ & & \\
\hline $\begin{array}{l}2 \\
7\end{array}$ & $\begin{array}{l}\text { Tillet et } \\
\text { al }\end{array}$ & $25 \mathrm{M}$ & USA & $\begin{array}{l}\text { Sy } \\
\text { m }\end{array}$ & No & Mild & $\begin{array}{l}18 \\
\text { Apr }\end{array}$ & $\begin{array}{l}\text { RT } \\
\text { PC } \\
\text { R }\end{array}$ & Yes & Yes & Yes & $\begin{array}{l}10 \\
\text { days } \\
\text { after } \\
\text { last } \\
\text { nega } \\
\text { tive } \\
\text { test }\end{array}$ & $\begin{array}{l}\text { RT } \\
\text { PCR }\end{array}$ & $\begin{array}{l}\text { Disc } \\
\text { harg } \\
\text { ed }\end{array}$ \\
\hline $\begin{array}{l}2 \\
8\end{array}$ & $\begin{array}{l}\text { Elslan } \\
\text { de et } \\
\text { al }\end{array}$ & $51 \mathrm{~F}$ & $\begin{array}{l}\text { Belgi } \\
\text { um }\end{array}$ & $\begin{array}{l}\text { Sy } \\
\text { m }\end{array}$ & $\begin{array}{l}\text { Asth } \\
\text { ma }\end{array}$ & $\begin{array}{l}\text { mod } \\
\text { erat } \\
\text { e }\end{array}$ & $\begin{array}{l}\text { Mar } \\
20\end{array}$ & $\begin{array}{l}\text { RT } \\
\text { PC } \\
\text { R }\end{array}$ & $\begin{array}{l}\text { Yes } \\
\text { (secon } \\
\text { d time) }\end{array}$ & No & Yes & $\begin{array}{l}10 \\
\text { wee } \\
\text { ks } \\
\text { after } \\
\text { hom } \\
\text { e } \\
\text { quar } \\
\text { antin } \\
\text { e }\end{array}$ & $\begin{array}{l}\text { RT } \\
\text { PCR }\end{array}$ & $\begin{array}{l}\text { Not } \\
\text { Hosp }\end{array}$ \\
\hline $\begin{array}{l}2 \\
9\end{array}$ & $\begin{array}{l}\text { Prado- } \\
\text { Vivar B } \\
\text { et al }\end{array}$ & $46 \mathrm{M}$ & $\begin{array}{l}\text { Euca } \\
\text { doria } \\
n\end{array}$ & $\begin{array}{l}\text { Sy } \\
\text { m }\end{array}$ & NM & Mild & $\begin{array}{l}\text { May } \\
12\end{array}$ & $\begin{array}{l}\text { RT } \\
\text { PC } \\
\text { R }\end{array}$ & Yes & Yes & Yes & $\begin{array}{l}6 \\
\text { wee } \\
\text { ks } \\
\text { after } \\
\text { bein } \\
\text { g } \\
\text { nega } \\
\text { tive }\end{array}$ & $\begin{array}{l}\text { RT } \\
\text { PCR }\end{array}$ & $\begin{array}{l}\text { Not } \\
\text { hosp }\end{array}$ \\
\hline $\begin{array}{l}3 \\
0\end{array}$ & $\begin{array}{l}\text { Vivek } \\
\text { gupta } \\
\text { et al }\end{array}$ & $\begin{array}{l}25 \mathrm{M} \\
28 \mathrm{~F}\end{array}$ & India & $\begin{array}{l}\text { As } \\
\text { ym }\end{array}$ & $\begin{array}{l}\text { No } \\
\text { No }\end{array}$ & $\begin{array}{l}\text { Asy } \\
\mathrm{m}\end{array}$ & $\begin{array}{l}05 \\
\text { May } \\
17 \\
\text { May }\end{array}$ & $\begin{array}{l}\text { RT } \\
\text { PC } \\
\text { R } \\
\text { RT } \\
\text { PC } \\
\text { R }\end{array}$ & NM & Yes & No & $\begin{array}{l}100 \\
\text { days } \\
\text { after } \\
\text { teste } \\
\text { d } \\
\text { nega } \\
\text { tive } \\
101 \\
\text { days }\end{array}$ & $\begin{array}{l}\text { RT } \\
\text { PCR }\end{array}$ & $\begin{array}{l}\text { Not } \\
\text { Hosp }\end{array}$ \\
\hline
\end{tabular}

